\title{
Perbandingan Kuat Tekan Dan Kuat Lentur Beton Mutu Tinggi Dengan Menggunakan Berbagai Merk Semen Di Kota Pekanbaru
}

\author{
Roza Mildawati ${ }^{1}$ \\ ${ }^{1}$ Fakultas Teknik Program Studi Teknik Sipil Universitas Islam Riau \\ email:rozamildawati@eng.uir.ac.id
}

\begin{abstract}
Abstrak
Beton merupakan bahan bangunan yang sangat popular digunakan dalam dunia jasa kontruksi, terdiri dari campuran Portland Cement (PC) atau semen hidrolik lainnya, agregat halus, agregat kasar dan air, dengan atau tanpa menggunakan bahan tambahan. Kualitas bahan seperti semen juga sangat berpengaruh terhadap kekuatan beton setelah mengeras, sehingga pemilihan kualitas semen harus sesuai dengan peraturan perencanaan beton agar mendapat hasil yang optimal. Di Indonesia sudah banyak pabrik semen baru yang memproduksi untuk memenuhi kebutuhan masyarakat, salah satunya yaitu semen merk Conch. Maka sehubungan dengan hal diatas, semen Conch dapat diteliti untuk dibandingan nilai kuat tekan dan kuat lenturnya dengan semen lama yaitu semen Padang, Tiga Roda, Holcim dan Bosowa yang umumnya selalu dipakai dalam perencanaan beton saat ini.

Tujuan penelitian ini untuk mengetahui nilai perbandingan kuat tekan dan kuat lentur beton dan faktor pengali antara semen Padang, Tiga Roda dan Conch pada umur 28 hari. Pada penelitian ini menggunakan metode SNI 03-2834-2000. Dengan benda uji silinder ukuran $(150 \mathrm{~mm}$ x $300 \mathrm{~mm})$ dan balok ukuran $(150 \mathrm{~mm}$ x $150 \mathrm{~mm}$ x $600 \mathrm{~mm}$ ) dibuat tiga benda uji untuk masing-masing semen.

Kuat tekan beton maksimum terdapat pada semen Padang dengan nilai kuat tekan 45,86 Mpa, untuk nilai kuat tekan minimum terdapat pada semen Tiga Roda dengan nilai kuat tekan 40,19 Mpa dan untuk nilai kuat tekan semen Conch terdapat pada peringkat kedua dengan nilai kuat tekan 42,84 Mpa. Dari penjelasan diatas hasil kuat tekan beton umur 28 hari dengan masing masing merk semen masih belum mencapai kuat tekan beton rencana sebesar $38 \mathrm{MPa}$. Kuat lentur beton maksimum terdapat pada semen Padang dengan nilai kuat lentur 5,03 Mpa, untuk nilai kuat lentur minimum terdapat pada semen Tiga Roda dengan nilai kuat lentur 3,96 Mpa dan untuk nilai kuat tekan semen Conch terdapat pada peringkat kedua dengan nilai kuat lentur 4,43 Mpa. Dari penjelasan diatas hasil kuat lentur beton umur 28 hari dengan masing masing merk semen yang belum mencapai rencana 4,4 Mpa yaitu merk semen tiga roda.
\end{abstract}

Kata Kunci : Semen, Kuat Tekan Beton, SNI 03-2834-2000. 


\section{PENDAHULUAN}

Beton merupakan bahan bangunan yang sangat popular digunakan dalam dunia jasa kontruksi, terdiri dari campuran Semen Portland (PC) atau semen hidraulik lainnya, agregat halus, agregat kasar dan air, dengan atau tanpa menggunakan bahan tambahan yang membentuk masa padat (SNI-032847-2002). Kekuatan tekan beton sangat dipengaruhi oleh umur dari beton itu sendiri. Semakin bertambahnya umur, beton akan mengalami perkembangan kekuatan, hingga pada suatu saat akan mencapai batas optimumnya.

Kualitas bahan seperti semen juga sangat berpengaruh terhadap kekuatan beton, sehingga pemilihan kualitas semen harus sesuai dengan peraturan perencanaan beton agar mendapatkan hasil yang optimal pada umur 28 hari (Prakoso, 2016). Di Indonesia sudah banyak berdiri pabrik semen yang mendistribusikan sampai kepelosok negeri demi memenuhi kebutuhan masyarakat dalam bidang konstruksi, khususnya di kota Pekanbaru sudah banyak terdapat berbagai macam merk semen yang diperjual belikan saat ini salah satunya semen Conch yang baru diperjual belikan di pasaran.

Berdasarkan penelitian terdahulu, telah banyak yang membandingkan kuat tekan beton dengan menggunakan berbagai merk semen, akan tetapi belum ada penelitian yang membandingkan dengan semen Conch dan masih jarang digunakan dalam proyek konstruksi di Pekanbaru, maka penelitian ini dilakukan untuk mengetahui perbandingan kuat tekan dan kuat lentur beton semen Conch terhadap semen Padang dan Tiga Roda pada umur 28 hari.

\section{TINJAUAN PUSTAKA}

Marsono (2017) dengan judul penelitian "Pengaruh Jenis Semen Terhadap Umur Beton Dan Kuat Tekan Beton”. Penelitian ini dilakukan di Laboratorium Struktur dan Teknologi Bahan Konstruksi, Jurusan Teknik Sipil, Universitas Muhammadiyah Yogyakarta. Tujuan dari penelitian ini adalah Mengkaji nilai slump dari beton yang menggunakan Semen Maerah Putih, Semen Bima, dan Semen Conch, mengkaji nilai kuat tekan dari beton yang menggunakan Semen Merah Putih, Semen Bima, dan Semen Conch pada umur 7 hari, 14 hari, dan 28 hari dengan menggunakan nilai fas 0,5 serta mengkaji nilai faktor pengali untuk kuat tekan beton pada umur 7 hari, 14 hari, dan 28 hari. Dalam penelitian ini mix design menggunakan metode Standar Nasional Indonesia (SK.SNI 032847-2002). Hasil dari pengujian didapakan nilai kuat tekan beton rata-rata pada umur 7 hari, 14 hari, dan 28 hari untuk beton yang menggunakan Semen Merah Putih adalah 12,77 MPa; 12,07 MPa; 19,20 MPa; untuk beton yang menggunakan Semen Bima adalah 12,48 $\mathrm{MPa}$; 13,34 MPa; 16,56 MPa; dan untuk beton yang menggunakan Semen Conch adalah 15,74 $\mathrm{MPa} ; 19,68 \mathrm{MPa}$; 17,59 MPa.

Prakoso (2016) dengan judul penelitian "Perbandingan Kuat Tekan Beton Pada Semen Bima Dan Semen Holcim Dengan Variasi Umur 7, 14, dan 28 Hari Menggunakan Nilai Fas 0,5”. Penelitian ini dilakukan di laboratorium Teknologi Bahan Konstruksi, Jurusan Teknik Sipil, Fakultas Teknik, Universitas Muhammadiyah Yogyakarta. Tujuan dari penelitian ini adalah Untuk mengetahui nilai kuat tekan beton yang dihasilkan pada umur 7, 14, dan 28 hari dengan menggunakan fas 0,5. Kemudian untuk mengetahui nilai perbandingan kuat tekan beton yang dihasilkan menggunakan Semen Bima dan semen Holcim, serta untuk mengetahui faktor pengali kuat tekan beton pada berbagai umur 7 hari, 14 hari, dan 28 hari. Dalam penelitian ini mix design menggunakan metode Standar Nasional Indonesia (SK.SNI 03-2847-2002). Dari hasil penelitian nilai kuat tekan beton pada umur 7 hari, 14 hari, dan 28 hari berturut turut untuk semen Bima adalah 21,48 $\mathrm{MPa}$; 22,60 $\mathrm{MPa} ; 31,34 \mathrm{MPa}$ dan untuk semen Holcim adalah 17,51 MPa, 20,27 MPa, 20,84 MPa. Perbandingan nilai kuat tekan beton semen Bima lebih besar dari semen 
Holcim dengan nilai selisih sebesar 10,50 MPa $(33,50 \%)$ pada umur 28 hari. Faktor pengali pada umur 7 hari, 14 hari, dan 28 hari berturut turut untuk semen Bima adalah 1,$48 ; 1,38 ; 1$, dan untuk semen Holcim 1,20; 1,02; 1.

Hidayat (2015) dengan judul penelitian "Perbandingan Kuat Tekan Beton Pada Berbagai Umur Dengan Menggunakan Beberapa Merk Semen Berdasarkan Sni". Penelitian ini dilakukan di laboratorium teknologi bahan dan beton Fakultas Teknik Sipil Universitas Islam Riau. Tujuan penelitian ini adalah untuk menentukan kuat tekan beton dengan menggunakan semen Padang, Holcim, Bosowa, Andalas tipe I, Tiga Roda tipe I dan untuk menentukan kuat tekan beton yang tertinggi pada umur 1, 3, 7, 14, dan 28 hari pada semen Padang, Andalas tipe I, Tiga Roda tipe I, Bosowa, dan Holcim. Pada penelitian ini menggunakan metode SK SNI T-151990-03. Dengan benda uji silinder ukuran (150 mm x $300 \mathrm{~mm}$ ) dan pengujian pada umur 1, 3, 7, 14, 28 hari. Dengan masingmasing hari dibuat 5 benda uji silinder di uji pada setiap umur. Dengan mutu beton yang direncanakan adalah fc' $25 \mathrm{Mpa}$, dengan faktor air semen $60-30 \mathrm{~mm}$. Dari hasil pengujian didapat kuat tekan rata-rata untuk campuran dengan komposisi yang sama didapat dengan menggunakan semen Bosowa 30,79 Mpa, semen Andalas tipe I 26,94 Mpa, semen Padang 30,92 Mpa dan semen Tiga roda tipe I 27,10 Mpa. Dapat dilihat semen Holcim memeiliki kuat tekan yang paling tinggi dari semen Bosowa, Andalas, Padang dan Tiga Roda.

\section{METODOLOGI PENELITIAN}

\subsection{Tahap Pelaksanaan Penelitian}

1. Persiapan

Meliputi pengurusan izin pemakaian labolatorium, persiapan material, bahan tambahan dan persiapan peralatan.

2. Pemeriksaan Material

Pemeriksaan material terdiri dari analisa saringan, barat isi agregat, berat jenis, kadar air dan kadar lumpur.

3. Perencanaan Campuran Beton
Metode yang digunakan dalam perhitungan campuran beton (mix design) berdasarkan SNI 03-2834-2000.

4. Pembuatan Beton Segar

Dalam pembuatan beton segar ini menggunakan mesin pengaduk beton.

5. Pengujian Nilai Slump Test

Pengujian slump test ini dimaksud untuk ukuran kelecakan beton segar yang berhubungan dengan tingkat kemudahan dalam pengerjaannya.

6. Pembuatan Benda Uji

Benda uji dibuat dengan menggunakan silinder dengan ukuran $150 \mathrm{~mm}$ x 300 $\mathrm{mm}$, dan balok ukuran $150 \mathrm{~mm} \times 150$ $\mathrm{mm}$ x $600 \mathrm{~mm}$ dengan benda uji 3 sampel tiap - tiap umur dan merk semen yang berbeda.

Tabel Jumlah Benda Uji Penelitian.

\begin{tabular}{|c|c|c|c|}
\hline \multirow{2}{*}{ No } & \multirow{2}{*}{ Merk Semen } & \multicolumn{2}{|c|}{$\begin{array}{c}\text { Umuraratan Beton } \\
\text { (Hari) }\end{array}$} \\
\cline { 3 - 4 } & silinder & Balok \\
\hline 1 & Semen Padang & 3 & 3 \\
\hline 2 & $\begin{array}{c}\text { Semen Tiga } \\
\text { Roda }\end{array}$ & 3 & 3 \\
\hline 3 & Semen Conch & 3 & 3 \\
\hline \multicolumn{2}{|c|}{ Jumlah Benda Uji } & 9 & 9 \\
\hline
\end{tabular}

(Sumber : Hasil Analisa Penelitian, 2018)

\section{Perawatan (curring)}

Dalam penelitian ini perawatan yang digunakan adalah perendaman dalam air, yang dilakukan di bak perendaman Laboratorium Universitas Islam Riau dengan umur 28 hari.

8. Pengujian Kuat Tekan Beton

Pengujian kuat tekan beton dimaksudkan untuk mencari perbandingan kuat tekan rencana dengan kuat tekan yang dihasilkan dari beberapa umur rencana 28 hari dari masing-masing semen.

9. Hasil dan Pembahasan

Analisa dan pembahasan didapat setelah pengujian benda uji beton, lalu dilakukan analisa kuat tekan benda uji beton terhadap umur benda uji dari masing-masing semen.

10. Kesimpulan dan Saran

Kesimpulan dan saran bertujuan menyimpulkan apa yang telah didapat 
dari hasil penelitian dan saran kepada peneliti selanjutnya.

\subsection{Analisa Data}

Analisis hasil penelitian dapat dilakukan setelah data-data diolah, Datadata yang dapat diolah mulai dari saat penelitian sampai akhir penelitian adalah sebagai berikut:

1. Data Pemeriksaan Agregat Halus.
a. Pemeriksaan kadar air
b. Pemeriksaan berat jenis
c. Pemeriksaan analisa saringan
d. Pemeriksaan kadar lumpur
e. Pemeriksaan berat volume
f. Pemeriksaan analisa data

2. Data Pemeriksaan Agregat Kasar.
a. Pemeriksaan kadar air
b. Pemeriksaan berat jenis
c. Pemeriksaan analisa saringan
d. Pemeriksaan kadar lumpur
e. Pemeriksaan berat volume
f. Pemeriksaan analisa data

3. Uji Slump.

4. Uji Kuat Tekan Beton.
a. Kuat tekan $\left(f c^{\prime}\right)$.
b. Kuat tekan rata-rata benda uji (fcr).
c. Standar deviasi $(S)$.
d. Kuat tekan karakteristik ( $f c k$ ).

5. Uji Kuat Lentur Beton.

Setelah semua data tersebut diolah menjadi tabel dan grafik persamaan maka dapat dilakukan analisis dan pembahasan terhadap data tersebut. Tahap selanjutnya setelah analisis dan pembahasan maka dapat ditarik kesimpulan serta saran. Bagan alir penelitian seperti yang terlihat pada Gambar 3.1 disajikan untuk mempermudah dalam proses pelaksanaan penelitian.

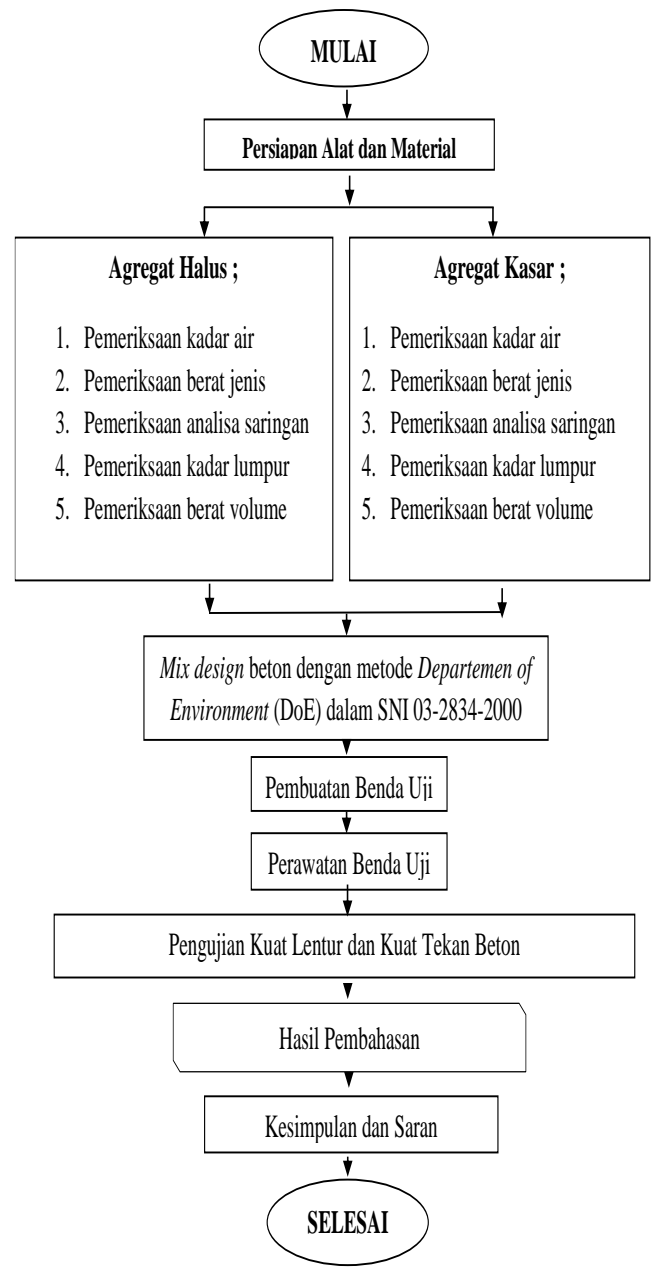

Gambar 3.1 Bagan Alir Penelitian

\section{HASIL DAN PEMBAHASAN}

\subsection{Material Benda Uji}

Bahan-bahan yang digunakan dalam penelitian ini adalah sebagai berikut semen yang digunakan yaitu semen Padang, Tiga Roda dan Conch. Agregat kasar yang digunakan adalah batu pecah yang berasal dari daerah Pangkalan Sumatera Barat, sedangkan agregat halus yang digunakan berasal dari Teratak Buluh - Kampar dan air yang dipakai adalah air telah memenuhi persyaratan yang terdapat dalam SK SNI 03-2834-2000 untuk lebih jelasnya dapat dilihat pada Tabel 4.1. 
Tabel 4.1 Material Benda Uji

\begin{tabular}{|c|c|l|}
\hline No & $\begin{array}{c}\text { Bahan- } \\
\text { bahan }\end{array}$ & \multicolumn{1}{|c|}{ Keterangan } \\
\hline 1. & Semen & Padang, Tiga Roda, Conch \\
\hline 2. & $\begin{array}{c}\text { Agregat } \\
\text { Halus }\end{array}$ & $\begin{array}{l}\text { Pasir dari Desa Teratak } \\
\text { Buluh - Kampar }\end{array}$ \\
\hline 3. & $\begin{array}{c}\text { Agregat } \\
\text { Kasar }\end{array}$ & $\begin{array}{l}\text { Batu pecah dari daerah } \\
\text { Pangkalan Sematera Barat }\end{array}$ \\
\hline 4. & Air & $\begin{array}{l}\text { Sumur bor Unit } \\
\text { Laboratorim Teknologi } \\
\text { Bahan dan Beton Fakultas } \\
\text { Teknik Universitas Islam } \\
\text { Riau }\end{array}$ \\
\hline
\end{tabular}

\subsection{Hasil Pemeriksaan Material Benda Uji}

Pemeriksaan material pada penelitian ini, meliputi pemeriksaan analisa saringan agregat halus dan agregat kasar, pemeriksaan berat jenis agregat halus dan agregat kasar, pemerikasaan berat isi agregat halus dan agregat kasar, pemeriksaan kadar air lapangan agregat halus dan agregat kasar. pemeriksaan kadar lumpur agregat halus dan agregat kasar.

\subsubsection{Hasil Pemeriksaan Agregat Halus}

Gradasi agregat halus dinyatakan dengan nilai persentase banyaknya agregat halus yang tertinggal atau melewati suatu susunan saringan 4,8 mm. Analisa saringan batas gradasi pasir dalam daerah pasir No.1, batas gradasi pasir dalam daerah pasir No.2,batas gradasi pasir dalam daerah pasir No.3, dan batas gradasi pasir dalam daerah pasir No.4. Hasil persentase lolos dapat dilihat dari Tabel 4.2

Tabel 4.2 Hasil Pemeriksaan Analisa Saringan Presentase Lolos Agregat Halus

\begin{tabular}{|c|c|c|c|c|c|c|c|c|c|c|}
\hline $\begin{array}{c}\text { Nomor } \\
\text { Ayakan }\end{array}$ & $1 \frac{1}{2}$ & $3 / 4$ & $3 / 8$ & $\# 4$ & $\# 8$ & $\# 16$ & $\# 30$ & $\# 50$ & $\# 100$ & $\# 200$ \\
\hline $\begin{array}{c}\text { Ukuran } \\
\text { Ayak (mm) }\end{array}$ & 38 & 19 & 9,6 & 4,8 & 2,4 & 1,2 & 0,6 & 0,3 & 0,15 & 0,075 \\
\hline $\begin{array}{c}\text { Lolos } \\
(\%)\end{array}$ & $\mathbf{1 0 0}$ & $\mathbf{1 0 0}$ & $\mathbf{9 9 , 5 0 1}$ & $\mathbf{9 8 , 1 2 0}$ & $\mathbf{8 9 , 2 3 5}$ & $\mathbf{7 3 , 1 4 6}$ & $\mathbf{5 8 , 6 0 1}$ & $\mathbf{2 8 , 6 5 8}$ & $\mathbf{4 , 0 9 7}$ & $\mathbf{1 , 2 9 5}$ \\
\hline
\end{tabular}

Dari penjelasan Tabel 4.2 bahwa aggregat tersebut termasuk pada zona no.2. Dapat dilihat saringan ukuran $0,15 \mathrm{~mm}$ persentase lolos sebesar $4,097 \%$. Saringan ukuran $0,3 \mathrm{~mm}$ persentase lolos sebesar $28,658 \%$. Saringan ukuran $0,6 \mathrm{~mm}$ persentase lolos sebesar 58,601\%. Saringan ukuran $1,2 \mathrm{~mm}$ persentase lolos sebesar $73,146 \%$. Saringan ukuran 2,4 $\mathrm{mm}$ persentase lolos sebesar $89,235 \%$. Saringan ukuran 4,8 $\mathrm{mm}$ persentase lolos sebesar $98,120 \%$. Untuk saringan ukuran 9,6 persentase lolos sebesar 99,501\% mm, 19 $\mathrm{mm}$ dan $38 \mathrm{~mm}$ masing-masing persentase lolos sebesar $100 \%$. Dari data tersebut terlihat bahwa persentase lolos saringan agregat halus berada diantara batas minimum dan maksimum pada setiap ukuran saringan.

\subsubsection{Hasil Pemeriksaan Agregat Kasar}

Hasil persentase lolos pada Tabel 4.3 dengan batas gradasi untuk besar butir maksimum $40 \mathrm{~mm}$.

Tabel 4.3 Hasil Persentase Lolos Agregat

\begin{tabular}{|c|c|c|c|c|c|c|c|c|c|c|}
\hline $\begin{array}{c}\text { Nomor } \\
\text { Ayaka } \\
\text { n }\end{array}$ & $\begin{array}{l}1 \\
\frac{1}{2} \\
\end{array}$ & $3 / 4$ & $3 / 8$ & \#4 & \#8 & $\begin{array}{c}\# 1 \\
6\end{array}$ & $\begin{array}{c}\# 3 \\
0\end{array}$ & $\begin{array}{c}\# 5 \\
0\end{array}$ & $\begin{array}{l}\# 1 \\
00\end{array}$ & $\begin{array}{c}\# 20 \\
0\end{array}$ \\
\hline $\begin{array}{c}\text { Ukura } \\
\text { n } \\
\text { Ayak } \\
(\mathbf{m m}) \\
\end{array}$ & $\begin{array}{l}3 \\
8\end{array}$ & 19 & 9,6 & 4,8 & 2,4 & 1,2 & 0,6 & 0,3 & $\begin{array}{c}0,1 \\
5\end{array}$ & $\begin{array}{l}0,0 \\
75\end{array}$ \\
\hline $\begin{array}{c}\text { Lolos } \\
(\%)\end{array}$ & $\begin{array}{l}\mathbf{1} \\
\mathbf{0} \\
\mathbf{0}\end{array}$ & $\begin{array}{c}55 \\
340\end{array}$ & $\begin{array}{c}4,0 \\
49\end{array}$ & $\begin{array}{c}1,8 \\
43\end{array}$ & $\begin{array}{l}1,3 \\
83\end{array}$ & $\begin{array}{l}1,2 \\
86\end{array}$ & $\begin{array}{l}1,2 \\
31\end{array}$ & $\begin{array}{l}1,1 \\
52\end{array}$ & $\begin{array}{l}1,0 \\
24\end{array}$ & $\begin{array}{l}\mathbf{0 , 7} \\
\mathbf{9 9}\end{array}$ \\
\hline
\end{tabular}

Dari Tabel 4.3 pemeriksaan analisa saringan untuk memperoleh distribusi besaran atau jumlah persentase butiran pada agregat kasar dan menentukan batas gradasi.

\subsubsection{Hasil Pemeriksaan Berat Jenis Serta Penyerapan Material}

Pemeriksaan berat jenis serta penyerapan air material dilakukan untuk 
mengetahui berat jenis kering permukaan jenuh SSD (saturated surface dry) serta untuk memperoleh angka berat jenis curah, dan berat jenis semu. Hasil pemeriksaan dapat dilihat pada Tabel 4.4.

Tabel 4.4 Hasil Pemeriksaan Berat Jenis Serta Penyerapan Material

\begin{tabular}{|c|c|c|c|c|c|}
\hline Material & $\begin{array}{c}\text { Ber } \\
\mathbf{a t} \\
\text { Jen } \\
\text { is }\end{array}$ & $\begin{array}{c}\text { Berat } \\
\text { Jenis } \\
\text { Permuk } \\
\mathbf{a a n} \\
\text { Jenuh }\end{array}$ & $\begin{array}{c}\text { Bera } \\
\mathbf{t} \\
\text { Jenis } \\
\mathbf{S e m} \\
\mathbf{u}\end{array}$ & $\begin{array}{l}\text { Penyera } \\
\text { pan }\end{array}$ & $\begin{array}{c}\text { Keteranga } \\
\mathbf{n}\end{array}$ \\
\hline $\begin{array}{c}\text { Agregat } \\
\text { Halus }\end{array}$ & $\begin{array}{c}2,61 \\
3\end{array}$ & 2,629 & 2,655 & 0,612 & $\begin{array}{c}\text { Memenuhi } \\
\text { Standar } \\
\text { Spesifikasi }\end{array}$ \\
\hline $\begin{array}{c}\text { Agregat } \\
\text { Kasar 2/3 }\end{array}$ & $\begin{array}{c}2,51 \\
6\end{array}$ & 2,570 & 2,66 & 2,153 & $\begin{array}{c}\text { Memenuhi } \\
\text { Standar } \\
\text { Spesifikasi }\end{array}$ \\
\hline $\begin{array}{c}\text { Agregat } \\
\text { Kasar 1/2 }\end{array}$ & 2,52 & 2,572 & 2,648 & 1,816 & $\begin{array}{c}\text { Memenuhi } \\
\text { Standar } \\
\text { Spesifikasi }\end{array}$ \\
\hline
\end{tabular}

Dari Tabel 4.4 dapat dilihat bahwa agregat halus, agregat kasar $2 / 3$ dan $1 / 2$ memiliki berat jenis permukaan jenuh $2,629,2,570$ dan 2,660, berdasarkan nilai berat jenis material tersebut dapat memenuhi standar spesifikasi berat jenis $\begin{array}{lllll}\text { yaitu } & 2,58 \quad \mathrm{~s} / \mathrm{d} & 2,83 & \mathrm{gr} / \mathrm{cm}^{3}\end{array}$ (Tjokrodimuljo,1995). Berat jenis kering permukaan jenuh ini merupakan sebagai pegangan untuk memperoleh berat jenis agregat campuran yang nantinya digunakan dalam menentukan perkiraan berat beton dalam $\mathrm{m}^{3}$.

\subsubsection{Hasil Pemeriksaan Kadar Air}

Pemeriksaan kadar air bertujuan untuk memperoleh persentase dari kadar air yang terkandung dalam agregat. Hasil pemeriksaan kadar air dapat dilihat pada Tabel 4.5

Tabel 4.5 Hasil Pemeriksaan Kadar Air Agregat

\begin{tabular}{|c|c|}
\hline Material & Kadar Air (\%) \\
\hline Agregat Halus & 0,381 \\
\hline Agregat Kasar 2/3 & 1,763 \\
\hline Agregat Kasar 1/2 & 1,123 \\
\hline
\end{tabular}

\subsubsection{Hasil Pemeriksaan Kadar Lumpur}

Pemeriksaan kadar lumpur ini menggunakan metode penjumlahan bahan dalam agregat yang lolos saringan \#200 $(0,075)$ yang dimaksudkan sebagai acuan dalam pegangan untuk melaksanakan pengujian dan untuk melakukan penjumlahan tersebut didapat setelah dilakukan pencucian benda uji. Hasil pemeriksaan dapat dilihat pada Tabel 4.6 berikut ini.

Tabel 4.6 Hasil Pemeriksaan Kadar Lumpur Agregat

\begin{tabular}{|c|c|c|}
\hline Material & $\begin{array}{c}\text { Kadar } \\
\text { Lumpur (\%) }\end{array}$ & Keterangan \\
\hline Agregat Halus & 0,979 & $\begin{array}{c}\text { Memenuhi } \\
\text { Standar } \\
\text { spesifikasi }\end{array}$ \\
\hline $\begin{array}{c}\text { Agregat Kasar } \\
\text { 2/3 }\end{array}$ & 0,77 & $\begin{array}{c}\text { Memenuhi } \\
\text { Standar } \\
\text { spesifikasi }\end{array}$ \\
\hline $\begin{array}{c}\text { Agregat Kasar } \\
1 / 2\end{array}$ & 0,85 & $\begin{array}{c}\text { Memenuhi } \\
\text { Standar } \\
\text { spesifikasi }\end{array}$ \\
\hline
\end{tabular}

Dari Tabel 4.6 dapat dilihat bahwa agregat halus mengandung kadar lumpur dalam keadaan memenuhi standar spesifikasi sehingga aman digunakan untuk campuran adukan beton, dimana kadar lumpur harus memenuhi persyaratan agregat halus < 5\% dan untuk agregat kasar $<1 \%$ (Tjokrodimuljo, 2007), sehingga material-material yang digunakan pada penelitian ini bisa langsung digunakan dan tidak perlu dicuci.

\subsection{Hasil Pemeriksaan Campuran Beton (SK SNI 03-2834-2000)}

Perencanaa campuran beton (Mix Design) bertujuan untuk mengetahui proporsi campuran antara semen, agregat halus, agregat kasar dan air. Hasil perencanaan campuran (Mix Design) beton untuk tiap $\mathrm{m}^{3}$ sesudah koreksi kadar air dapat dilihat pada tabel 4.7, hasil perencanaan campuran beton untuk 3 benda uji slinder sesudah koreksi kadar air dapat dilihat Tabel 4.8 .

Tabel 4.7 Proporsi Campuran Beton (Mix Desing) Untuk Tiap $\mathrm{m}^{3}$ Sebelum Koreksi Kadar Air SSD (Saturated Surface Dry). 


\begin{tabular}{|l|c|c|c|c|}
\hline $\begin{array}{c}\text { Propersi } \\
\text { Campura } \\
\mathbf{n}\end{array}$ & $\begin{array}{c}\text { Seme } \\
\mathbf{n} \\
(\mathbf{k g})\end{array}$ & $\begin{array}{c}\text { Air } \\
\text { (kg) }\end{array}$ & $\begin{array}{c}\text { Agrega } \\
\text { t Halus } \\
\text { (kg) }\end{array}$ & $\begin{array}{c}\text { Agrega } \\
\text { t Kasar } \\
\text { (kg) }\end{array}$ \\
\hline Tiap m3 & 425 & 170 & 526,02 & 1257,1 \\
\hline $\begin{array}{l}\text { Tiap 1 Zak } \\
\text { semen }\end{array}$ & 50 & 20 & 61,88 & 147,9 \\
\hline $\begin{array}{l}\text { Tiap } \\
\text { komp. } \\
\text { Camp. }\end{array}$ & 1 & 0,40 & 1,24 & 2,950 \\
\hline
\end{tabular}

Berdasarkan Tabel 4.7 dapat dilihat pemakaian semen, air, agregat halus, dan agregat kasar dalam tiap $\mathrm{m}^{3}$, tiap 1 zak semen dan tiap komposisi campuran. Sebelum dilakukan koreksi kadar air didapat proporsi campuran beton untuk 3 benda uji silinder yang dapat dilihat pada Tabel 4.8 dan 4.9.

Tabel 4.8 Proporsi Campuran Beton (Mix Design) Untuk 3 Benda Uji Slinder Ukuran $15 \mathrm{~cm}$ x $30 \mathrm{~cm}$ Sesudah Koreksi Kadar Air SSD (Saturated Surface Dry).

\begin{tabular}{|c|l|c|}
\hline No & $\begin{array}{c}\text { Material } \\
\text { Campuran }\end{array}$ & $\begin{array}{c}\text { Proporsi } \\
\text { Campuran } \\
\text { Untuk 1x } \\
\text { Adukan (kg) }\end{array}$ \\
\hline 1 & Semen & 8,12 \\
\hline 2 & Air & 3,15 \\
\hline 3 & Agregat Halus & 10,02 \\
\hline 4 & $\begin{array}{l}\text { Agregat Kasar } \\
2 / 3\end{array}$ & 14,35 \\
\hline 5 & $\begin{array}{l}\text { Agregat Kasar } \\
1 / 2\end{array}$ & 9,54 \\
\hline
\end{tabular}

Tabel 4.9 Proporsi Campuran Beton (Mix Design) Untuk 1 Benda Uji Balok Ukuran $15 \mathrm{~cm}$ x $15 \mathrm{~cm}$ x $60 \mathrm{~cm}$ Sesudah Koreksi Kadar Air SSD (Saturated Surface Dry).

\begin{tabular}{|c|l|c|}
\hline No & \multicolumn{1}{|c|}{$\begin{array}{c}\text { Material } \\
\text { Campuran }\end{array}$} & $\begin{array}{c}\text { Proporsi } \\
\text { Campuran } \\
\text { Untuk 1x } \\
\text { Adukan (kg) }\end{array}$ \\
\hline 1 & Semen & 6,88 \\
\hline 2 & Air & 2,67 \\
\hline 3 & Agregat Halus & 8,50 \\
\hline 4 & $\begin{array}{l}\text { Agregat Kasar } \\
2 / 3\end{array}$ & 12,17 \\
\hline 5 & $\begin{array}{l}\text { Agregat Kasar } \\
1 / 2\end{array}$ & 8,50 \\
\hline
\end{tabular}

\subsection{Hasil dan Analisa Nilai Slump Beton}

Hasil pemeriksaan dari slump test bertujuan untuk mengecek adanya perubahan kadar air yang ada dalam adukan beton, sedangkan nilai slump dimaksudkan untuk mengetahui kosesistensi beton dan sifat workability (kemudahan dalam pengerjaan) beton sesuai dengan syaratsyarat yang ditetapkan, semakin rendah nilai slump menunjukan beton semakin kental dan proses pemadatan atau pekerjaan beton akan mengalami kesulitan dan butuh waktu cukup lama. Dalam proses pengerjaan atau pemadatan lebih mudah dilaksanakan dan tidak memerlukan waktu yang lama dalam proses pemadatannya. Dari penelitian yang telah dilakukan dapat dilihat nilai slump pada Tabel 4.10.

Tabel 4.10 Hasil Slump Test Beton

\begin{tabular}{|c|c|c|}
\hline No & Merk Semen & $\begin{array}{c}\text { Nilai Slump } \\
\text { Rata-Rata }(\mathbf{C m})\end{array}$ \\
\hline 1 & Padang & 3,20 \\
\hline 2 & Tiga Roda & 3,36 \\
\hline 3 & Conch & 3,44 \\
\hline
\end{tabular}

Nilai slump beton untuk lebih jelasnya dapat dilihat pada Gambar 4.1.

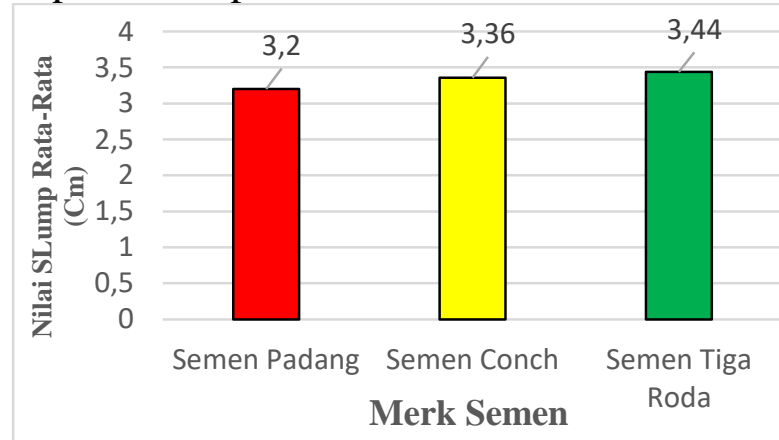

Gambar 4.1 Hasil Slump Rata-Rata

Dari Gambar 4.1 dapat dijelaskan setiap semen memiliki tingkat kekentalan yang berbeda- beda. Terlihat bahwa semen Padang, semen Tiga Roda dan semen Conch memperoleh nilai Slump rata-rata $3,2 \mathrm{~cm}, 3,36 \mathrm{~cm}$ dan $3,44 \mathrm{~cm}$ sudah memenuhi persyaratan yang direncanakan yaitu $30-60 \mathrm{~mm}$.

\subsection{Hasil Analisa Kuat Tekan Beton (SNI 03-2834-2000)}


Pengujian kuat tekan beton dilaksanakan setelah masa perawatan (curing) benda uji berusia 28 hari untuk masing-masing hari benda uji dibuat sebanyak 3 buah benda uji untuk 1 merk semen.

\subsubsection{Beton Umur 28 Hari Benda Uji Silinder}

Dari hasil pengujian beton benda uji silinder dengan menggunakan alat kuat tekan (compressive stength machine) benda uji silinder maka didapat hasil untuk masing-masing hari perawatan dari masingmasing merk semen yang berbeda., hasil uji kuat tekan beton dapat dilihat pada Tabel 4.11 .

Tabel 4.11 Hasil Uji Kuat Tekan Beton

\begin{tabular}{|c|c|c|c|}
\hline \multirow{2}{*}{$\begin{array}{c}\text { Umur } \\
\text { perawatan } \\
\text { beton (hari) }\end{array}$} & \multicolumn{3}{|c|}{ Umur 28 hari } \\
\cline { 2 - 4 } & \multicolumn{3}{|c|}{ Jenis Semen } \\
\cline { 2 - 4 } & Padang & $\begin{array}{c}\text { Tiga } \\
\text { Roda }\end{array}$ & Conch \\
\hline 28 & 47,56 & 39,06 & 43,03 \\
\hline 28 & 45,86 & 39,63 & 41,89 \\
\hline 28 & 44,16 & 39,63 & 43,59 \\
\hline$f \boldsymbol{c}^{\prime} \boldsymbol{r}$ & $\mathbf{4 5 , 8 6}$ & $\mathbf{4 0 , 1 9}$ & $\mathbf{4 2 , 8 4}$ \\
\hline$f \boldsymbol{c}^{\prime} \boldsymbol{k}$ & $\mathbf{4 3 , 0 7}$ & $\mathbf{3 7 , 6 9}$ & $\mathbf{4 1 , 4 1 2}$ \\
\hline $\boldsymbol{f c}^{\prime}{ }_{\text {rencana }}$ & $\mathbf{3 8}$ & $\mathbf{3 8}$ & $\mathbf{3 8}$ \\
\hline
\end{tabular}

Dari Tabel 4.11 dapat dibuat dalam bentuk grafik seperti Gambar 4.2.

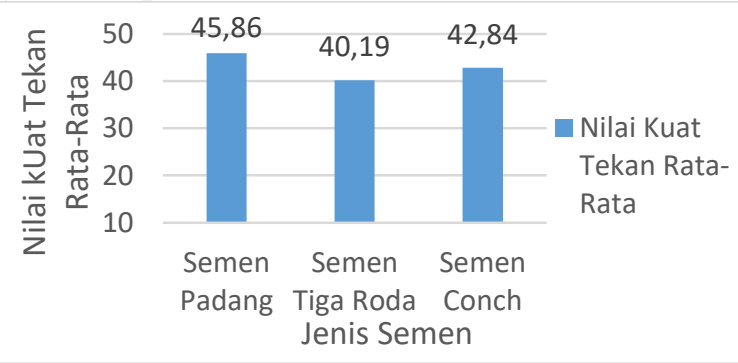

Gambar 4.2 Hasil Kuat Tekan Beton Selama Umur 28 Hari

Dari Gambar 4.2 dapat dilihat nilai kuat tekan beton maksimum terdapat pada semen Padang dengan nilai kuat tekan 45,86 Mpa, untuk nilai kuat tekan minimum terdapat pada semen Tiga Roda dengan nilai kuat tekan 40,19 Mpa dan untuk nilai kuat tekan semen Conch terdapat pada peringkat kedua dengan nilai kuat tekan
42,84 Mpa. Dari penjelasan diatas hasil kuat tekan beton umur 28 hari dengan masing masing merk semen masih belum mencapai kuat tekan beton rencana sebesar $38 \mathrm{MPa}$.

\subsubsection{Beton Umur 28 Hari Benda Uji Balok \\ Dari hasil pengujian beton benda uji} silinder dengan menggunakan alat kuat lentur benda uji balok maka didapat hasil untuk masing-masing hari perawatan dari masing-masing merk semen yang berbeda., hasil uji kuat lentur beton dapat dilihat pada Tabel 4.12.

Tabel 4.12 Hasil Uji Kuat Lentur Beton Umur 28 hari

\begin{tabular}{|c|c|c|c|}
\hline \multirow{2}{*}{$\begin{array}{c}\text { Umur } \\
\text { perawatan } \\
\text { beton (hari) }\end{array}$} & \multicolumn{3}{|c|}{ Kuat Lentur (Mpa) } \\
\cline { 2 - 4 } & Padang & $\begin{array}{c}\text { Tiga } \\
\text { Roda }\end{array}$ & Conch \\
\cline { 2 - 4 } & 5,12 & 3,75 & 4,55 \\
\hline 28 & 4,93 & 3,97 & 4,74 \\
\hline 28 & 5,02 & 4,17 & 4,02 \\
\hline 28 & $\mathbf{5 , 0 3}$ & $\mathbf{3 , 9 6}$ & $\mathbf{4 , 4 3}$ \\
\hline fs rata-rata & $\mathbf{4 , 4}$ & $\mathbf{4 , 4}$ & $\mathbf{4 , 4}$ \\
\hline fs rencana & & & \\
\hline
\end{tabular}

Dari Tabel 4.12 dapat dibuat dalam bentuk grafik seperti Gambar 4.3.

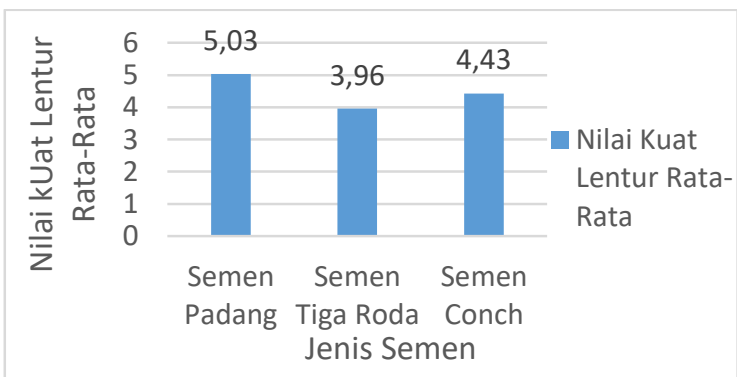

Gambar 4.3 Hasil Kuat Lentur Beton Selama Umur 28 Hari

Dari Gambar 4.3 dapat dilihat nilai kuat lentur beton maksimum terdapat pada semen Padang dengan nilai kuat lentur 5,03 Mpa, untuk nilai kuat lentur minimum terdapat pada semen Tiga Roda dengan nilai kuat lentur 3,96 Mpa dan untuk nilai kuat tekan semen Conch terdapat pada peringkat kedua dengan nilai kuat lentur 4,43 Mpa. Dari penjelasan diatas hasil kuat 
lentur beton umur 28 hari dengan masing masing merk semen yang belum mencapai rencana 4,4 Mpa yaitu merk semen tiga roda.

\section{KESIMPULAN DAN SARAN}

\subsection{Kesimpulan}

Berdasarkan penelitian yang telah dilakukan terhadap korelasi kuat tekan beton mutu tinggi terhadap umur beton dengan menggunakan semen yang beredar di kota Pekanbaru, maka dapat disimpulkan sebagai berikut:

1. Kuat tekan beton maksimum terdapat pada semen Padang dengan nilai kuat tekan 45,86 Mpa, untuk nilai kuat tekan minimum terdapat pada semen Tiga Roda dengan nilai kuat tekan 40,19 Mpa dan untuk nilai kuat tekan semen Conch terdapat pada peringkat kedua dengan nilai kuat tekan 42,84 Mpa. Dari penjelasan diatas hasil kuat tekan beton umur 28 hari dengan masing masing merk semen masih belum mencapai kuat tekan beton rencana sebesar $38 \mathrm{MPa}$.

2. kuat lentur beton maksimum terdapat pada semen Padang dengan nilai kuat lentur 5,03 Mpa, untuk nilai kuat lentur minimum terdapat pada semen Tiga Roda dengan nilai kuat lentur 3,96 Mpa dan untuk nilai kuat tekan semen Conch terdapat pada peringkat kedua dengan nilai kuat lentur 4,43 Mpa. Dari penjelasan diatas hasil kuat lentur beton umur 28 hari dengan masing masing merk semen yang belum mencapai rencana 4,4 Mpa yaitu merk semen tiga roda.

\subsection{Saran}

Berdasarkan penelitian yang telah dilakukan terhadap perbandingan kuat tekan beton pada berbagai umur dengan menggunakan beberapa merk semen. Maka penulis menyampaikan babarapa saran yang terkait pada penelitian ini, antara lain sebagai berikut:
1. Untuk penelitian selanjutnya disarankan dapat menggunkan merk semen yang lebih banyak lagi, agar lebih mengetahui semen mana yang lebih tinggi mutu betonnya dengan harga yang murah dan kualitas yang lebih baik.

2. Untuk penelitian selanjutnya bisa menggunakan bahan tambah zat adictive untuk membandingkan hasil penelitian diatas.

\section{DAFTAR PUSTAKA}

ASTM C33, 2004. "Standard Specification For Concrete Aggregates", Annual Books of ASTM Standard, USA.

Departemen Pekerjaan Umum, 2005. Pedoman Awal Untuk Perkiraan Proporsi Takaran Campuran.

Dipohusodo, Istimawan, 1999. Struktur Beton Bertulang Berdasarkan SK SNI T-15-1991-03. Jakarta: PT. Gramedia Pustaka Utama.

Heinz, 1999. Penentuan Banyaknya Air Per $\mathrm{M}^{3}$ Beton, Yogyakarta.

Mulyono, T, 2004. Teknologi Beton, Edisi Kedua, Andi, Yogyakarta.

Nilson, A, 1993. Perencanaan Struktur Beeton Bertulang, Edisi Pertama, Paramita Pradnya, Jakarta.

Nugraha, P dan Antoni, 2007. Teknologi Beton, Edisi Pertama, Andi, Yogyakarta.

Samekto, W., 2001. Teknologi Beton, Edisi Kelima, Kanisius, Yogyakarta.

Santoso, Slamet. Analisis Regresi Dan Korelasi (Materi VIII : Analisis Regresi dan Korelasi Sederhana). http://ssantoso.blogspot.co.id/2008/0 8/analisis-regresi-dan-korelasimateri.html?m=1. 7 Agustus 2008. Diakses Pada 17 Januari 2018 Pukul 14.00 .

SNI 03 - 2834 - 2000. Tata Cara Pembuatan Rencana Campuran Beton Normal

SNI 03 - 2847 - 2002. Tata Cara Perhitungan Struktur Beton Untuk Bangun Gedung (Beta Version). 
Subakti, 1999. Teknologi Beton Dalam

Praktek, Jurusan Teknik Sipil,

Fakultas Tenik ITS, Surabaya.

Tjokrodimulyo, Kardioyono, 1992.

Teknologi Beton. Biro Penerbit,

Yogyakarta.

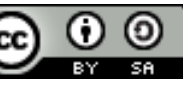

This is an open access article which means that all content is freely available without charge to the user or his/her institution. Jurnal Saintis allows the author(s) to hold the copyright without restriction. The copyright in the text of individual articles (including research articles, opinion articles, and abstracts) is the property of their respective authors distributed under the terms of the Creative Commons Attribution-ShareAlike 4.0 International License(https://creativecommons.org/licenses/by-sa/4.0/) which permits unrestricted use, distribution, and reproduction in any medium. Users are allowed to read, download, copy, distribute, search, or link to full-text articles in this journal without asking by giving appropriate credit, provide a link to the license, and indicate if changes were made. 